\title{
THE ACCURACY AND QUALITY OF IMMUNISATION INFORMATION SYSTEMS IN FORTY-ONE LOW INCOME COUNTRIES
}

Xavier Bosch-Capblanch, Olivier Ronveaux, Vicki Doyle, Valerie Remedios, Abdallah Bchir

Xavier Bosch-Capblanch. Public Health Consultant. Liverpool Associates in Tropical Health (at the time of the study)

Olivier Ronveaux. Vaccine Assessment and Monitoring, Vaccines and Biologicals. World Health Organization (at the time of the study)

Vicki Doyle. Head of Technical Delivery. Liverpool Associates in Tropical Health.

Valerie Remedios. Pharmaceutical Programme Manager. Euro Health Group. Abdallah Bchir. Senior Program Officer | Monitoring and Evaluation. GAVI Alliance

Correspondence to Xavier Bosch-Capblanch. Swiss Centre for International Health / Swiss Tropical Institute. Socinstrasse 57. CH-4002. Basel (Switzerland) Phone; +41612848 319; email: x.bosch@unibas.es

\section{CONFLICT OF INTEREST}

A Bchir works in the GAVI secretariat and O Ronveaux in WHO. The other authors work or have worked full or part time in one of the consortiums involved in the implementation of DQAs. The funding source was not involved in the study design; collection, analysis or interpretation of data; writing of the paper or the decision to submit the paper for publication. 


\section{ABSTRACT}

\section{Objectives}

To measure the accuracy and quality of immunisation information systems in a range of low-income countries eligible to receive GAVI support.

\section{Methods}

The Data Quality Audit (DQA) uses a WHO validated, standard methodology to compare data collected from health unit $(\mathrm{HU})$ records of immunisations administered with reports of immunisation at central level and to collect quality indicators of the reporting systems. The Verification Factor (VF), as a measure of accuracy, expresses the proportion of immunisations reported at national level that can be tracked down to the HU. A VF of $80 \%$ or above entitles countries to receive additional GAVI financial support. Quality indicators are assigned points which were summed to obtain quality scores (QS) at national, district and $\mathrm{HU}$ levels.

DQAs were conducted between 2002 and 2005 in 41 countries, encompassing 1082 primary health care units in 188 randomly selected districts.

\section{Results}

Almost half of countries obtained a VF below $80 \%$ and only nine showed consistently high VF and QS scores. The most frequent weaknesses identified in the information systems included: inconsistency of denominators used to estimate coverage, poor availability of guidelines (e.g. for late reporting), incorrect estimations of vaccine wastage and lack of feedback on immunization performance. In all six countries that failed a first DQA and undertook a second DQA the VF and all QSs improved, not all of them statistically significantly.

\section{Conclusions}

The DQA is a diagnostic tool to reveal a number of crucial problems that affect the quality of immunisation data in all tiers of the health system. It identifies good performance at $\mathrm{HU}$ and district levels which can be used as examples of best practices. The DQA methodology brings data quality issues to the top of the agenda to improve the monitoring of immunisation coverage. 


\section{INTRODUCTION}

Routine immunisation is one of the most cost-effective public health interventions (The World Bank 1993) to reduce child mortality (Jones et al. 2003). Global immunisation coverage of systematic vaccines has been steadily increasing since the eighties (WHO 2006). However, global figures mask great inequalities between geographical regions and population sectors (WHO 2006, Pearson 2003). It has been estimated that almost 18 million infants have not received the first dose of Diphtheria-Tetanus-Pertussis vaccine (DTP), half of them living in Southeast Asia and one third of them in Africa (Anonymous 2006).

The GAVI Alliance (GAVI), launched in the year 2000, is one of the global health partnerships that have emerged in recent years aiming at improving access to known effective health care interventions (Walt and Buse 2000). GAVI's mission is to save children's lives and to protect people's health through the widespread use of vaccines (GAVla). It focuses on the 72 countries (in 2006) with a Gross National Income (GNI) per capita below 1,000 USD (GAVIc), where most of the unimmunised children live (WHO 2006).

GAVI's support to countries include immunisation services (ISS), injection safety, new and underused vaccines, health systems strengthening and civil society organisation support (GAVlb). ISS is provided in two phases: an investment phase (years one and two) and the reward phase (from year three onwards). During the latter, countries receive 20 USD per additional infant who has received DTP3 (third dose of DTP) as compared to baseline figures (GAVId). However, this reward is contingent to providing evidence that data reported by countries are reliable, as assessed with Data Quality Audits (DQA).

The aim of any initiative to improve immunisation is to increase coverage up to a level where all children are protected against the targeted diseases. However, it has been increasingly recognised, that good quality information for decisionmaking is essential to increase coverage (Papania M and Rodewald 2006, Bchir et al. 2006). Surveillance, monitoring and evaluation are integral components of successful immunisation systems (WHO/UNICEF 2005).

DQA is a survey methodology developed by the World Health Organisation (WHO) which estimates the robustness of immunisation reporting systems. The main outcome of DQAs is the estimation of the Verification Factor (VF), which expresses the accuracy of the reporting system by estimating the proportion of DTP3 immunisations that can be traced through the reporting system, from the vaccine delivery points up to the national coverage estimates. GAVI partners agreed that countries with a VF of $80 \%$ or more would 'pass' and receive the reward while countries that 'fail' are required to produce their own plans to improve the reporting system and are encouraged to conduct a second DQA two years later (The LATH Consortium 2001).

A previous paper (Ronveaux et al. 2005) reviewed the methodological issues of DQA and focused on the aggregated outcomes of the DQAs conducted up to 2003. In this report, we present individual countries' performance of the DQA carried out in 41 countries up to 2005, and explore patterns of performance among countries. We also show the changes in the reporting system in those countries that failed the first DQA and undertook a second one. Since DQA do not aim at estimating immunisation coverage, we will not do any comparison with other methods to estimate immunisation coverage. 


\section{METHODS}

DQA is a standard methodology developed by the WHO; it is carried out by independent companies after an open tender process. Two external consultants travelled to each country and engaged with two staff members of the national immunisation programmes to conduct the DQAs over a period of two weeks.

In each country, a multistage sampling procedure was followed: first, four districts were randomly selected with probability proportional to the reported doses of DTP3 administered in the previous year; secondly, in each of the four districts, six Health Units (HU), where immunisations are administered, were randomly selected (total of 24 HUs per country). This weighted representative sampling was designed to fit with what could be reasonably achieved within the resources and timeframe of the DQA. Districts and HUs with unsolvable access problems which make them non-eligible were excluded from the sampling process. Reasons for exclusion were mainly security situations or major geographical barriers that could not be overcome within the timeframe of a field visit. DQAs with a proportion of unreachable districts greater than $20 \%$ have been excluded from some of the analyses and indicated in the text.

DQAs have two outcome measures: the VF and the Quality Scores (QS). The period audited was the full calendar year previous to the date when the DQA took place.

In each district, the VF is calculated by dividing the number of DTP3 vaccinations administered during the audited year as recounted in the HUs records filled at the very moment when children are vaccinated by the annual DTP3 vaccinations reported in the HUs reports found at the health district offices (the usual next tier in the reporting system). This quotient is adjusted for the weight of the six selected HUs in relation to the whole number of HUs in the district. This is finally extrapolated to the national level as the weighed average of districts VFs. The methods and mathematical expressions have been described in detail elsewhere (Ronveaux et al. 2005, WHO 2003).

A VF less than $100 \%$ indicates that the reports at district level showed more DTP3 administrations than those that could be recounted at HU level ('overreporting'); a VF over $100 \%$ suggests that not all DTP3 doses recounted could be traced in the reports at district level ('under-reporting').

QSs were based on a series of questions and observations undertaken at each level of the immunisation programme: national, district and HU. They covered topics such as recording and reporting of immunisation data, keeping of vaccine ledgers and information system design. Each question correctly answered was assigned one point. An average QS ranging from 0 to 5 was obtained for the national level, for each one of the four districts and for each one of the $24 \mathrm{HUs}$ (some questions for each level of the system differed).

Finally, auditors provided feed-back to immunisation staff at all levels and suggested recommendations addressing the most relevant issues identified.

\section{Statistical analyses}

Summary Quality Scores for each level are presented as medians and interquartile ranges of the QS estimated for each country, district and HU. Correlation between continuous variables was estimated using Spearman's rank test since we could not assume that their errors followed a normal distribution. Differences between medians were tested using the Mann-Whitney test in SPSS 13.0 (SPSS Inc. 1989-2004). 


\section{RESULTS}

Forty seven DQAs were conducted between 2002 and 2005 in 41 countries: 30 African, 9 Asian, 1 Middle-Eastern and 1 Caribbean. 21 countries failed the DQA (VF less than $80 \%$ ), and six of those conducted a second DQA (total 47 DQAs).

The proportion of non-eligible districts for sampling was higher than $20 \%$ in nine of the 41 DQAs: $55 \%$ in Yemen, $45 \%$ in Nepal, $43 \%$ in Myanmar, $41 \%$ in Congo, 34\% in Afghanistan, 32\% in Lesotho, 32\% in Sudan's second DQA, $25 \%$ in DR Congo and $22 \%$ in Mali. A total of 1,082 HUs were surveyed in 188 districts in the 47 DQAs. Table 1 summarises the country profiles and DQA framework.

The VF (data accuracy) was below the threshold value (80\%) in $46 \%$ of the DQAs (median of the VF 83\%, inter-quartile range (IQR) 23\%) (Figure 1). Excluding those DQAs with high proportion of unreachable districts: $50 \%$ had a VF below $80 \%$ and the median of the VF was $80 \%$ (IQR $33 \%$ ). In Nigeria it was not possible to estimate the VF due to a lack of data. Two DQAs showed VFs above $100 \%$, indicating under-reporting (the deviation from $100 \%$ was marginal: $100.2 \%$ and $106.4 \%)$.

VF $95 \%$ confidence intervals (CI) were wide, especially in countries with low VFs, reflecting the great variability of the DTP3 recounted-reported quotient among districts. DQAs with VFs above 95\% showed very narrow Cls, suggesting homogeneity in the VFs among districts. There was a significant correlation between VFs and the widths of its Cls (rho $=-0.679, p<0.001$ ).

Table shows a selection of the questions to assess the quality of the immunisation reporting system in each tier, with the percentage of countries, districts and HUs that correctly answered them, excluding DQAs with a high proportion of unreachable districts.

In theory, immunisation reporting mechanisms can be integrated within the national health management information systems or can be set apart as a parallel vertical reporting system only for immunisation. DQAs showed that reporting of immunisation data from the $\mathrm{HU}$ to the district level was integrated in $61 \%$ of the DQAs; and from the district to the national level in $55 \%$ of DQAs.

Computers to manage immunisation data were used in all national immunisation programme offices and in $41 \%$ of district offices. In almost three quarters of the DQAs, immunisation data was used to provide feed-back from the national to the district immunisation offices; slightly more than half of districts provided feed-back to the HUs under their catchment area. Immunisation data was also compiled in some type of publication in $82 \%$ of national immunisation offices and $58 \%$ of districts. However, immunisation monitoring charts or tables could only be seen in less than half of the national immunisation offices, $59 \%$ of districts and in a smaller proportion of HUs. DTP13 drop-out rates were monitored in a lesser proportion at all three levels. A relatively high proportion of $\mathrm{HUs}$ had some immunisation reports or primary recording forms available, but only two thirds had a complete set of reports from the previous year.

The use of consistent denominators is essential to obtain accurate immunisation coverage figures. Almost all national immunisation programmes 
used different figures in different years, reflecting the change in population size. However this was not the case in Districts with $87 \%$ using the same figures in different years. In $82 \%$ of the DQAs, denominators complied with the WHO recommended definition. In only $14 \%$ of the DQAs it was found that districts were using consistent denominators to those assigned by the national immunisation programmes to each district within a country.

The presence of guidelines for different immunisation related procedures was variable. At district level, guidelines seemed to be more available than at national level.

Vaccine ledgers to manage vaccine stocks could be found in the majority of national immunisation programmes, in district offices and HUs holding vaccine stocks, however, a smaller proportion were updated. Vaccine wastage calculations could be confirmed in almost one third of national programmes and district offices and in two thirds of HUs.

The answers to these questions were used to estimate QS for each level of the immunisation reporting system. The median QS at national level was 3.3 out of 5.0 (inter-quartile range 0.7 ), 3.3 out of 5.0 (inter-quartile range 1.1) in the 152 districts and 3.1 out of 5.0 (inter-quartile range 1.6) in the 912 HUs across all districts and countries.

\section{Correlation analyses}

Figure 2 is a scatter chart depicting one 'bubble' per DQA, with the $X$ and $Y$ axis showing the aggregated $\mathrm{HU}$ and district QSs, respectively. The size of the 'bubbles' is proportional to the QS measured at national immunisation headquarters.

There was a significant correlation between QSs measured at $\mathrm{HU}$ and at district levels ( $r$ o $=0.865, p<0.001$ ). Larger 'bubbles' tended to be found towards the upper right corner of the chart suggesting a significant correlation of national QSs with district and HUs scores ( $r h o=0.525, p<0.001$ and rho $=0.4843, p=$ 0.002 , respectively).

Figure 2 identifies countries with consistent poor or good performances. Central African Republic, Haiti, Lao, Madagascar, Mauritania, Mozambique and Nigeria are in the lower left corner with small size bubbles: showing poor QS at all levels. At the far right upper end, Tanzania, Burkina Faso, Guinea (second DQA) and Kenya (second DQA) show the highest scores (DQAs with a high proportion of unreachable districts, excluded).

We also explored to what extent there could be examples of good quality districts (good district QS) in the poorest performing countries (poor national QS). QSs at national level significantly correlated with those of the best performing district in each country (rho $=0.408, p=0.004$ ). Looking at pairs of national-QS and best district QS in that country data, there were several cases of outstanding performance at district level in countries with very poor national QSs (Ethiopia, Tajikistan and Yemen) and also cases of consistent poor national QSs with even the best districts also poorly performing (Central African Republic, Haiti, Madagascar, Mauritania and Nigeria).

The VF did not show any significant correlation with national QS (rho $=0.211, p$ $=0.202$ ). On the contrary, there were significant correlations with districts and HUs QS (rho $=0.703, p<0.001$ and rho $=0.726, p<0.001$ respectively). .(DQAs with a high proportion of unreachable districts, excluded). 


\section{Countries with two DQAs}

From the 21 countries that failed the first DQA, six countries undertook a second DQA, two to three years later: Burkina Faso, Cameroon, Guinea, Kenya, Madagascar and Sudan. Data from the second DQA in Sudan has to be interpreted with caution since $25 \%$ of districts were unreachable.Table 2 summarises the changes in VFs and QSs between both DQAs in each country. VFs improved in all cases. 95\% $\mathrm{Cl}$ narrowed in all cases except Cameroon. However, first and second DQAs' VFs overlapped in all countries except Madagascar, suggesting that the true values of the VFs may actually not differ.

At national level, the median change of QS across the six countries was +0.7 . Looking at some examples of improvement: five of the six countries could estimate vaccine wastage in the second DQA while none of them could in the first one; in the second DQA, four countries had guidelines for electronic data management and for reporting AEFI while only one and none had them in the first one, respectively.

At district level, the median change of the QS was +1.1. In all six countries, districts showed better use of immunisation performance monitoring tools (tables and charts showing coverage), better vaccine record keeping and had guidelines in place for late reporting.

At HU level, the median change of the QS was +2.0. HU QS improved statistically significantly in all six countries (see Table 3). Quality items that improved in all cases included the management of vaccine ledgers, the availability of reports and tally sheets and the display of an updated chart or table showing immunisation performance indicators. 


\section{DISCUSSION}

\section{Data accuracy}

Sources of bias in the estimation of immunisation coverage have been widely described elsewhere and include inconsistencies in the reporting systems (WHO 2006), which DQAs detect through the VF. Poor information systems do not only fail to portray the real situation of immunisation coverage but are themselves barriers for scaling-up immunisation (GAVI 2003a, Papania M, Rodewald 2006,).

The VF expresses the deviation of national coverage estimates from their sources at HUs, where immunisations take place and the primary data is recorded in the first instance. These deviations can be partially explained by some of the findings in the systems quality questions. For example, there were missing primary records and reports (how many of these ever existed?) or guidelines for late reporting were frequently not found (how is information received after the termination of the reporting period actually treated?). The same problem was found when vaccine wastage could not calculated. These findings highlight basic problems in the production, storage and reporting of immunisation data in countries with poor VFs. Not surprisingly, VF correlated well with QS at HU and district levels, which are the sources of primary immunisation data.

Guidelines and training manuals on immunisation, which include monitoring and data management, are easily available (WHO 2004a) and extensive training has taken place in many countries (Mutabaruka at al. 2005). Why, then, do the basic administrative and reporting practices seem not to have been followed in those countries with poor DQA outcomes? Many determinants of performance at sub-national and local levels have been described (Mays et al. 2006), including remuneration, working conditions and factors directly related to health workers performance (Rowe et al. 2005). Whether this is pointing at a lack of knowledge or a poor organisational environment is beyond what DQAs can answer. However, we think that training on immunisation issues will need to take into account the basics of recording, reporting and data management practices and look in detail at the organisational environment needed to translate knowledge into effective, routine practice.

\section{Countries}

The best performing countries achieved excellent VFs and QSs. Central African Republic, low in all QS, had a good VF. At the other extreme, Haiti, Madagascar, Mauritania and Nigeria showed consistently poor performance at all levels of the immunisation reporting system.

Should poor performing countries be penalised without additional funding under a performance-based system, as it has been the case with GAVI's rewards? (GAVI 2006). Could a system aiming at rewarding performance and ensuring transparency end up having adverse effects on those countries in most need of help? Would countries facing a performance-based system feel tempted to generate some 'creative' reporting to increase rewards (Brugha $\mathrm{R}$ et al.) or to redirect their efforts to increase overall coverage rather than reducing in-country inequities (Starling et al. 2006)?. The answers to these questions are not straightforward. First, there are multiple factors which determine immunisation 
performance, including health system and contextual factors; secondly, in real life situations it is hardly possible to have "control" countries to establish sound comparisons in order to describe key determinants of success or failure. Our findings, though, identified several countries that showed consistent poor performance and that may call for special attention. Nigeria, for example, was the only country where the VF could not even be calculated due to the lack of data, it has one of highest numbers of unimmunised children in the world (WHO 2006) and had more than half the cases of polio in 2006 (Global Polio Eradication Initiative). GAVI has wisely responded to those concerns by considering separate policies for "fragile states" (Brugha R et al.).

Furthermore, districts within countries showed very different performance levels in the DQAs outcomes, suggesting that, besides nation-wide factors, there might be local determinants that may contribute to find very good performing districts in not so good performing countries, as seen in the cases of Ethiopia or Tajikistan.

\section{DQAs as inducers of change}

DQAs are an assessment tool. However, one of the outcomes of DQAs is the issuing of recommendations to assist HUs, districts and national immunisation programmes to improve their reporting systems (GAVI 2003b). Therefore, DQAs aim to induce change, as well.

Neither the design of DQAs nor the number of countries that undertook two DQAs can generate enough evidence to attribute the observed improvements to the DQAs themselves. However, in those countries that undertook two DQAs, improvements in the VFs were consistent with improvements in the QS, and showed statistically significant changes in the QSs at $\mathrm{HU}$ level. These improvements could be due to a 'learning effect' of the DQA method by countries, although districts and HUs in both DQAs were randomly selected and repetitions are very unlikely. DQAs certainly were an opportunity to raise quality issues and increase awareness on the consequences of poor data quality for programme management. Indeed, there is some evidence that failure to 'pass' a DQA has led to specific efforts (e.g. investment) in reporting information systems in a number of countries (Guinea, Laos, Tanzania and Zambia) (Abt Associates Inc. 2007).

DQAs have a number of limitations (Ronveaux et al. 2005), some of them analysed in detail (Woodard et al. 2007); namely the wide $\mathrm{Cl}$ of the VF, more imprecise at the medium and low ranges of the VF, the lack of verification of immunisations actually administered to children and the number of non-eligible districts in a few countries.

\section{Conclusion}

DQA is a systematic methodology to describe in depth data quality issues and to provide recommendations to address them. DQAs can reveal a number of crucial problems that affect the quality of immunisation data and provide countries with an opportunity to identify the weakest parts in the collection, transmission and use of information. Basic recording and reporting practices at the periphery of the system, alongside design aspects (e.g. denominators), have been identified as key factors that need to be tackled. DQAs also provide insights from all tiers of the health system, identifying good practices in some 
HUs and districts even in countries poorly performing as a whole. Those HUs and districts can become drivers to improve reporting mechanisms in the countries. DQAs have been adapted into a self-assessment tool (WHO 2004b) and can be simplified to assess specific aspects of the information system. In whatever form, DQAs bring data quality issues to the top front of the agenda to improve the monitoring of immunisation coverage. Furthermore, the DQA methodology could be considered to address data quality issues across the spectrum of national disease control programmes (The Global Fund 2007) so data quality remains at the top of the national agenda to help improve planning and service delivery based on accurate coverage estimates. 


\section{ACKNOWLEDGMENTS}

DQAs were conducted with financing of the Vaccine Fund and the analysis of this set of data by WHO (Vaccine Assessment and Monitoring), number $\mathrm{HQ} / 05 / 051359$.

We thank Lorelei Silvester (LATH) for the administrative support; lan Hastings, Brian Faragher (Liverpool School of Tropical Medicine) and Amanda Ross (Swiss Tropical Institute) for their contributions to the statistical methods. Charles Collins, Maria Paz Loscertales, Rete Trap and more specially Birna Trap, made suggestions about the manuscript at several stages.

We also thank the staff of the immunisation programmes at national, district and health unit levels for their open and intense collaboration during the implementation of the DQAs.

\section{TABLES AND FIGURES}


$X$ Bosch-Capblanch. The accuracy of the immunisation information systems

Table 1. Country profiles and DQA framework

\begin{tabular}{|c|c|c|c|c|c|c|c|c|}
\hline Region & Country & $\begin{array}{l}\text { Country } \\
\text { code }\end{array}$ & $\begin{array}{c}\text { Number } \\
\text { of } \\
\text { districts }\end{array}$ & $\begin{array}{c}\text { Under } \\
1 \mathrm{~s} \text { in } \\
\text { audit } \\
\text { year } \\
\times 1000\end{array}$ & $\begin{array}{l}\text { GNI (*) } \\
\text { per } \\
\text { capita } \\
\text { (USD) }\end{array}$ & $\begin{array}{l}\text { Number } \\
\text { of DQA }\end{array}$ & Year audited & $\begin{array}{l}\text { Health } \\
\text { units } \\
\text { visited }\end{array}$ \\
\hline \multirow[t]{30}{*}{ Africa } & Burkina Faso & BFA & 53 & 504 & 211 & 2 & 2001,2004 & 48 \\
\hline & Burundi & BDI & 17 & 260 & 91 & 1 & 2002 & 24 \\
\hline & Cameroon & CMR & 144 & 663 & 579 & 2 & 2001, 2003 & 45 \\
\hline & $\begin{array}{l}\text { Central African } \\
\text { Republic }\end{array}$ & CAF & 22 & 134 & 281 & 1 & 2003 & 24 \\
\hline & Chad & TCD & 53 & 302 & 437 & 1 & 2004 & 24 \\
\hline & Congo & COG & 27 & 148 & 780 & 1 & 2004 & 24 \\
\hline & Congo DR & COD & 481 & 2,245 & 111 & 1 & 2003 & 24 \\
\hline & Côte d'Ivoire & CUV & 46 & 674 & 594 & 1 & 2001 & 24 \\
\hline & Eritrea & ERI & 6 & 107 & 210 & 1 & 2003 & 24 \\
\hline & Ethiopia & ETH & 71 & 2,352 & 99 & 1 & 2001 & 23 \\
\hline & Ghana & GHA & 120 & 756 & 256 & 1 & 2001 & 21 \\
\hline & Guinea & GIN & 38 & 329 & 345 & 2 & 2001, 2003 & 44 \\
\hline & Kenya & KEN & 85 & 1,158 & 353 & 2 & 2001, 2003 & 48 \\
\hline & Lesotho & LSO & 19 & 48 & 736 & 1 & 2003 & 24 \\
\hline & Liberia & LBR & 18 & 118 & 121 & 1 & 2004 & 24 \\
\hline & Madagascar & MDG & 111 & 599 & 252 & 2 & 2002,2004 & 48 \\
\hline & Mali & MLI & 58 & 421 & 241 & 1 & 2001 & 24 \\
\hline & Mauritania & MRT & 53 & 113 & 390 & 1 & 2003 & 23 \\
\hline & Mozambique & MOZ & 12 & 689 & 198 & 1 & 2001 & 14 \\
\hline & Niger & NER & 42 & 550 & 158 & 1 & 2002 & 24 \\
\hline & Nigeria & NGA & NA & 5,054 & 345 & 1 & 2002 & 24 \\
\hline & Rwanda & RWA & 39 & 338 & 195 & 1 & 2001 & 22 \\
\hline & Senegal & SEN & 50 & 429 & 447 & 1 & 2002 & 24 \\
\hline & Sierra Leone & SLE & 14 & 219 & 193 & 1 & 2003 & 24 \\
\hline & Sudan & SDN & 129 & 1,001 & 365 & 2 & 2001, 2003 & 46 \\
\hline & Tanzania & TZA & 135 & 1,377 & 271 & 1 & 2001 & 24 \\
\hline & Togo & TGO & 35 & 199 & 295 & 1 & 2003 & 21 \\
\hline & Uganda & UGA & 64 & 1,022 & 224 & 1 & 2001 & 24 \\
\hline & Zambia & ZMB & 72 & 425 & 319 & 1 & 2002 & 24 \\
\hline & Zimbabwe & ZWE & 59 & 365 & 387 & 1 & 2003 & 24 \\
\hline \multirow[t]{10}{*}{ Asia } & Afghanistan & AFG & 32 & 943 & 141 & 1 & 2002 & 24 \\
\hline & Bangladesh & BGD & 64 & 3,202 & 389 & 1 & 2001 & 24 \\
\hline & Cambodia & KHM & 73 & 412 & 256 & 1 & 2002 & 24 \\
\hline & Korea DPR & PRK & 206 & 420 & 579 & 1 & 2003 & 24 \\
\hline & Lao PDR & LAO & 18 & 159 & 315 & 1 & 2002 & 24 \\
\hline & Myanmar & MMR & 320 & 1,350 & 191 & 1 & 2003 & 24 \\
\hline & Nepal & NPL & 75 & 737 & 221 & 1 & 2002(‡) & 24 \\
\hline & Pakistan & PAK & 115 & 5,262 & 498 & 1 & 2002 & 24 \\
\hline & Tajikistan & TJK & 62 & 161 & 158 & 1 & 2001 & 19 \\
\hline & Yemen & YEM & 286 & 599 & 498 & 1 & 2002 & 20 \\
\hline Caribbean & Haiti & $\mathrm{HTI}$ & 11 & 286 & 457 & 1 & 2001 & 16 \\
\hline TOTALS & 41 & Countries & 3,335 & 36,130 & - & 47 & - & 1,082 \\
\hline \multicolumn{3}{|c|}{ MEAN PER COUNTRY } & 83 & 881 & 322 & - & - & 26 \\
\hline
\end{tabular}

Data on regions, countries (UNa, UNb) and per capita GNI (UNc) were obtained from official United Nations statistics. $\left({ }^{*}\right)$ Gross National Income per capita in US Dollars; $(\dagger)$ Proportion of funds provided by the governments for financing the Expanded Programme of Immunisation (data for year 2004); ( $¥$ ) Audit year 2001-2002. 
Table 2. Performance in a selection of quality questions at the three levels

\begin{tabular}{|c|c|c|c|}
\hline Quality question & $\begin{array}{l}\% \text { of the } 38 \\
\text { DQAs }\end{array}$ & $\begin{array}{l}\% \text { of the } 152 \\
\text { districts }\end{array}$ & $\begin{array}{c}\% \text { of } 912 \\
\text { HUs }\end{array}$ \\
\hline $\begin{array}{l}\text { Integration of immunisation reporting systems } \\
\text { from HUs to district level }\end{array}$ & $61 \%$ & $N A(\|)$ & NA \\
\hline $\begin{array}{l}\text { Integration of immunisation reporting systems } \\
\text { from district to national level }\end{array}$ & $55 \%$ & NA & NA \\
\hline Use of computers to manage immunisation data & $100 \%$ & $41 \%$ & NA \\
\hline Feed-back on immunisation to lower level & $71 \%$ & $53 \%$ & NA \\
\hline Publication with immunisation data & $82 \%$ & $58 \%$ & NA \\
\hline $\begin{array}{l}\text { Existence of chart or table showing immunisation } \\
\text { performance indicators }\end{array}$ & $45 \%$ & $59 \%$ & $53 \%$ \\
\hline Monitoring DPT1-3 drop out rate & $35 \%\left(^{*}\right)$ & $46 \%(†)$ & $55 \%(\ddagger)$ \\
\hline Availability of current tally sheets for DPT & NA & NA & $82 \%$ \\
\hline Availability of reports & NA & NA & $65 \%$ \\
\hline $\begin{array}{l}\text { Use of different denominators according to year } \\
\text { to estimate DTP3 coverage }\end{array}$ & $97 \%$ & $87 \%$ & NA \\
\hline $\begin{array}{l}\text { Denominators for DTP3 defined according to } \\
\text { WHO definitions }\end{array}$ & $82 \%$ & NA & NA \\
\hline $\begin{array}{l}\text { Denominators used at national and district levels } \\
\text { coincide }\end{array}$ & $14 \%\left(^{*}\right)$ & NA & NA \\
\hline Existence of data reporting guidelines & $74 \%$ & $89 \%$ & NA \\
\hline Existence of guidelines to deal with late reporting & $13 \%$ & $50 \%$ & NA \\
\hline Existence of guidelines to report $\mathrm{AEFI}(\S)$ & $32 \%$ & $54 \%$ & $83 \%$ \\
\hline Existence of vaccine ledgers & NA & $88 \%$ & $85 \%$ \\
\hline Vaccines ledgers are up to date for DTP & $79 \%$ & $72 \%$ & $65 \%(\ddagger)$ \\
\hline Vaccines ledgers are up to date for $\mathrm{TT}\left({ }^{* *}\right)$ & $84 \%$ & $75 \%$ & $49 \%$ \\
\hline Correct estimation of vaccine wastage & $32 \%$ & $31 \%$ & $68 \%$ \\
\hline
\end{tabular}

$\left({ }^{*}\right)$ In 23 DQAs; (†) in 92 districts; ( $\left.\ddagger\right)$ in 552 HUs. (§) AEFI: Adverse Events Following Immunisation. (\|) NA: not assessed at that level. $\left.{ }^{(*}\right)$ Tetanus Toxoid vaccine. 
Table 3. Compared performance of countries that undertook two DQAs

\begin{tabular}{|c|c|c|c|c|c|c|c|}
\hline \multirow[t]{3}{*}{ Countries } & \multirow{3}{*}{$\begin{array}{c}\begin{array}{c}\text { Year } \\
\text { DQAs }\end{array} \\
2001\end{array}$} & \multicolumn{3}{|c|}{ Verification factor } & \multicolumn{3}{|c|}{ Quality Scores } \\
\hline & & \multicolumn{3}{|c|}{$95 \% \mathrm{Cl}$} & \multirow{2}{*}{$\begin{array}{c}\text { National } \\
3.2\end{array}$} & \multirow{2}{*}{$\begin{array}{c}\text { Distrital } \\
3.3\end{array}$} & \multirow{2}{*}{$\begin{array}{c}\mathrm{HU} \\
2.5\end{array}$} \\
\hline & & $58 \%$ & $19 \%$ & $96 \%$ & & & \\
\hline \multirow[t]{3}{*}{ Burkina Faso } & 2004 & $96 \%$ & $81 \%$ & $111 \%$ & 3.9 & 4.3 & 4.4 \\
\hline & Change & $+38 \%$ & & & +0.7 & +1.0 & $+1.9 \quad\left(^{*}\right)$ \\
\hline & 2001 & $48 \%$ & $15 \%$ & $81 \%$ & 3.6 & 2.9 & 2.1 \\
\hline \multirow[t]{3}{*}{ Cameroon } & 2003 & $89 \%$ & $53 \%$ & $125 \%$ & 4.3 & 4.4 & 4.1 \\
\hline & Change & $+41 \%$ & & & +0.7 & +1.5 & $+2.0 \quad\left(^{*}\right)$ \\
\hline & 2001 & $57 \%$ & $1 \%$ & $113 \%$ & 3.0 & 3.3 & 3.5 \\
\hline \multirow[t]{3}{*}{ Guinea } & 2003 & $95 \%$ & $92 \%$ & $99 \%$ & 3.4 & 4.2 & 4.5 \\
\hline & Change & $+38 \%$ & & & +0.4 & +0.9 & $+1.0 \quad\left(^{*}\right)$ \\
\hline & 2001 & $50 \%$ & $8 \%$ & $91 \%$ & 3.4 & 3.1 & 2.3 \\
\hline \multirow[t]{3}{*}{ Kenya } & 2003 & $85 \%$ & $68 \%$ & $103 \%$ & 4.0 & 4.1 & 4.3 \\
\hline & Change & $+35 \%$ & & & +0.6 & +1.0 & $+2.0 \quad\left(^{*}\right)$ \\
\hline & 2002 & $58 \%$ & $42 \%$ & $75 \%$ & 2.4 & 2.7 & 2.3 \\
\hline \multirow[t]{3}{*}{ Madagascar } & 2004 & $100 \%$ & $83 \%$ & $117 \%$ & 3.5 & 4.4 & 4.0 \\
\hline & Change & $+42 \%$ & & & +1.1 & +1.7 & $+1.7 \quad\left(^{*}\right)$ \\
\hline & 2001 & $69 \%$ & $18 \%$ & $121 \%$ & 2.6 & 2.7 & 2.1 \\
\hline \multirow[t]{2}{*}{ Sudan } & 2003 & $96 \%$ & $89 \%$ & $103 \%$ & 4.5 & 3.9 & 4.1 \\
\hline & Change & $+27 \%$ & & & +1.9 & +1.2 & $+2.0 \quad\left(^{*}\right)$ \\
\hline
\end{tabular}

Cl: confidence interval; $\left({ }^{*}\right) \mathrm{p}<0.001$ comparing the median QS of the 24 HUs in both years. 
Figure 1. Verification factors (VF) and DTP3 coverage (WHO-UNICEF) in the 47 DQAs

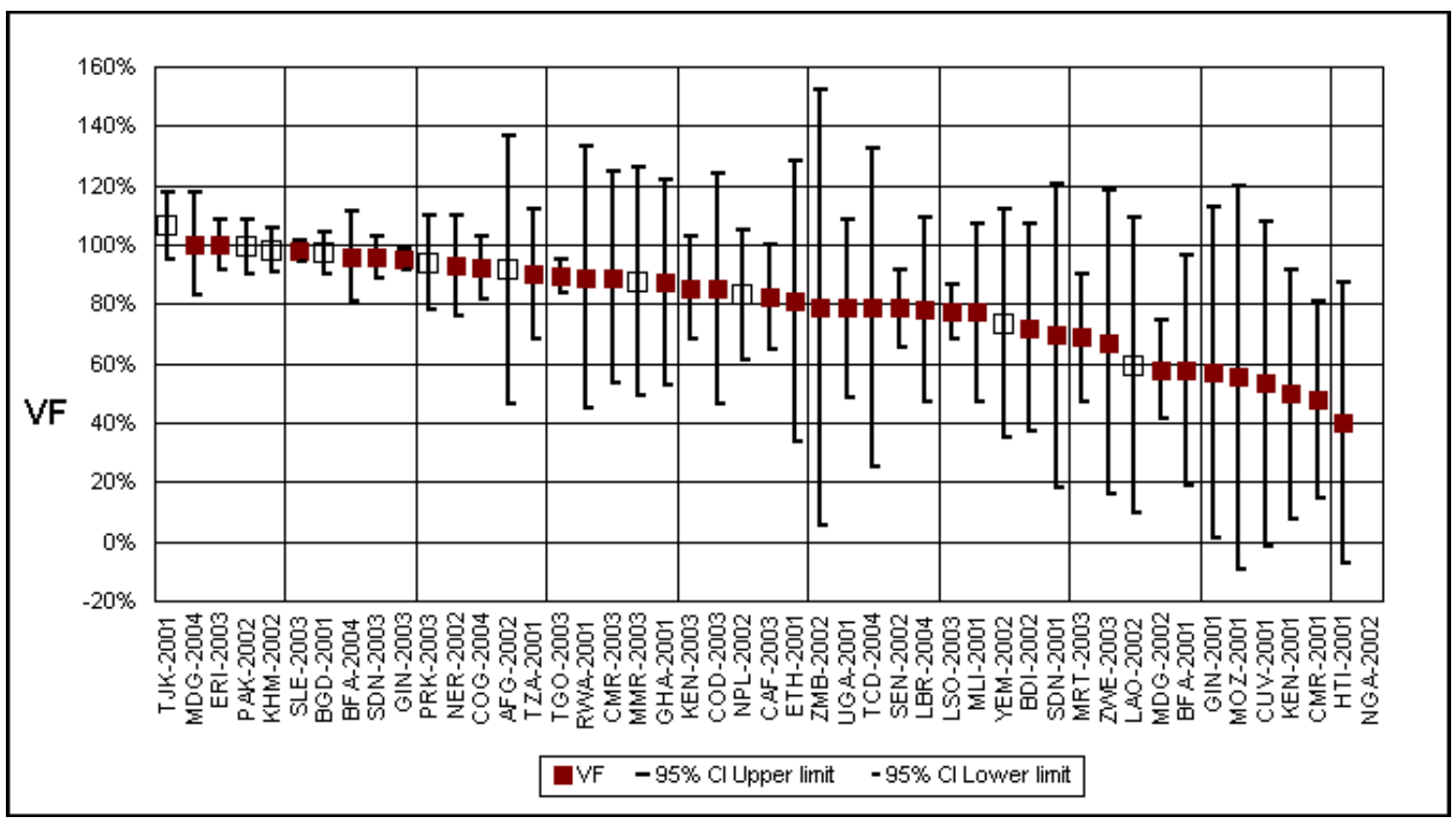

Footer:

$\mathrm{Cl}$ : confidence intervals. VF: Verification Factor. Solid squares: African countries and Haiti; empty squares: Asian countries and Yemen. 
Figure 2. Scatter chart for the quality scores (QS) at the three levels

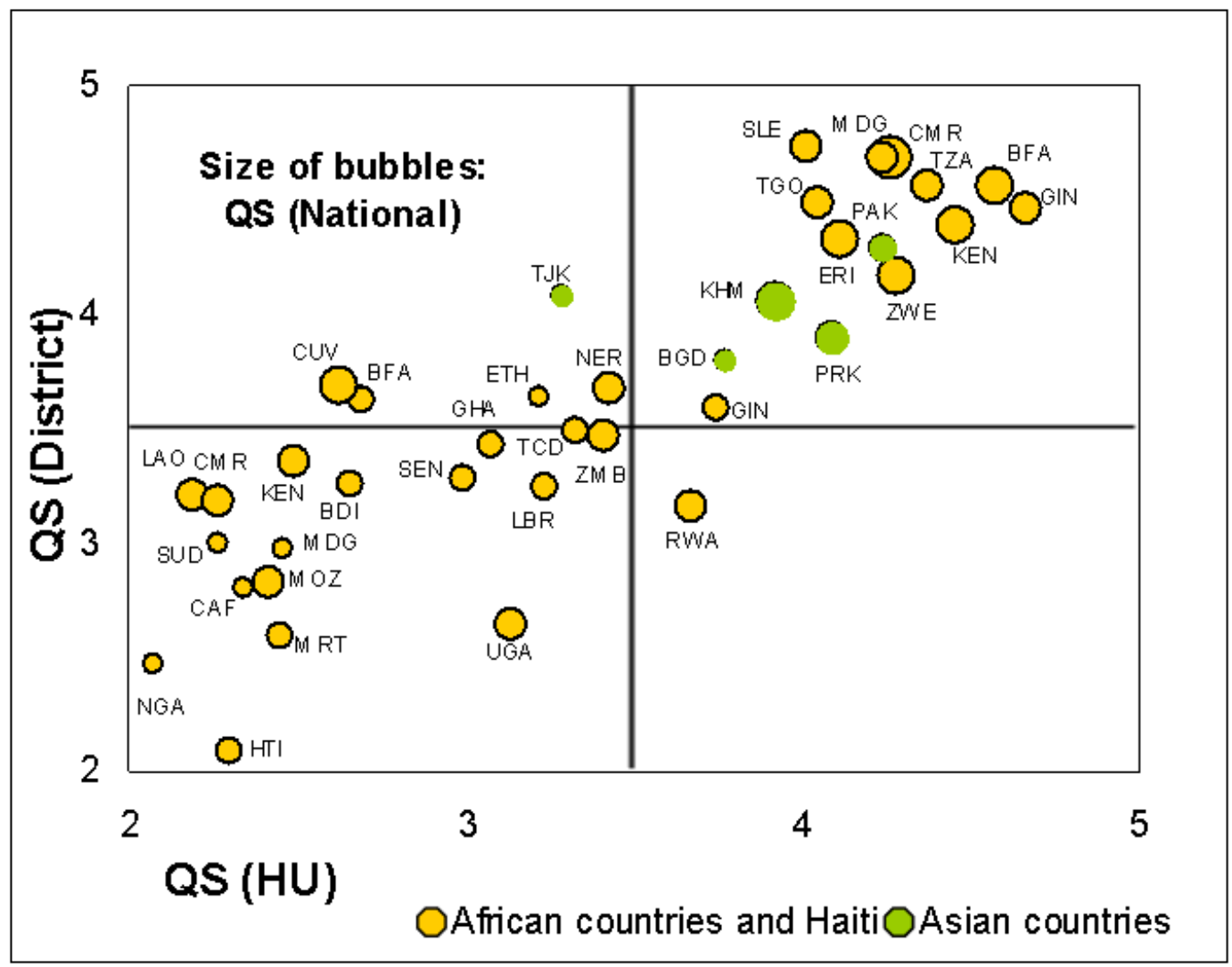

Footer:

Good correlation between QS is shown by many "bubbles" lying relatively close to the diagonal of the chart and their size growing from the lower-left up to the upper-right corners. 


\section{REFERENCES}

Abt Associates Inc (2007). Evaluation of the first five years of GAVI Immunisation Services Support funding.

Anonymous (2006). Challenges in global immunization and the Global Immunization Vision and Strategy 2006-2015. Weekly Epidemiological Record 81, 190-4

Bchir A, Bhutta Z, Binka F, Black R, Bradshaw D, Garnett G, Hayashi K, Jha P, Peto R, Sawyer C, Schwartländer B, Walker N, Wolfson M, Yach D, ZabaB (2006). Better health statistics are possible. Lancet. 367, 190-3.

Brugha R, Starling M, Walt G. GAVI, the first steps: lessons for the Global Fund. Lancet . 359, 435-8.

GAVla [homepage in the Internet]. What is GAVI? Available from: http://www.vaccinealliance.org/General_Information/About_alliance/index.php (accessed 11/01/2006).

GAVIb. What you can apply for. Available from:

http://www.gavialliance.org/support/what/index.php (accessed 17/12/2007).

GAVIc [homepage in the Internet]. web page. Summary of eligibility for support from GAVI and The Vaccine Fund. Available from:

http://www.vaccinealliance.org/Support_to_Country/Who_can_Apply/index.php (accessed 11/01/2006).

GAVId. Immunisation services support (ISS). Available from: http://www.gavialliance.org/support/what/iss/index.php (accessed 17/12/2007).

GAVI (2003a). Achieving our immunisation goal. Final report.

GAVI (2003b). How to prepare for a Data Quality Audit. Briefing paper.

Available from: http://gavi.elca-services.com/resources/DQABriefPaper02.pdf

GAVI (2006). Improving GAVI's Engagement and Effectiveness in Fragile

States. GAVI Alliance Board Meeting, 29/11/2006 (for decision).

Global Polio Eradication Initiative. Wild poliovirus weekly update. Available from: http://www. polioeradication.org/casecount.asp (accessed 18/12/2007).

Jones G, Steketee RW, Black RE, Bhutta ZA, Morris SS and the Bellagio Child Survival Study Group (2003). How many deaths can we prevent this year? Lancet. 362, 65-71.

Mays GP, McHugh MC, Shim K, Perry N, Lenaway D, Halverson PK, Moonesinghe R (2006). Institutional and economic determinants of Public Health System performance. Am J Public Health. 96(3), 523-31.

Mutabaruka E, NshimirimanaD, Goilav C, Meheus A (2005). EPI training needs assessment in 12 African countries (2002-2004). WHO-Afro. Available from: http://www.afro.who.int/ddc/vpd/tfi2005/tna_2002_2004.pdf.

Papania M, Rodewald L (2006). For better immunisation coverage, measure coverage better (Comment). Lancet. 367, 965-6.

Pearson M (2003). Improving the health of the Nigerian people. DFID Health Systems Resource Centre.

Ronveaux O, Rickert D, Hadler S, Groom H, Lloyd J, Bchir A, Birmingham M (2005). The immunisation data quality audit: verifying the quality and 
consistency of immunisation monitoring systems. Bulletin of the World Health Organization. 83(7), 503-10.

Rowe AK, de Savigny D, Lanata CF, Victoria CG (2005). How can we achieve and maintain high-quality performance of health workers in low-resource settings? Lancet. 366, 1026-35.

Starling M, Brugha R, Walt G (2002). New Products into Old Systems. The Global Alliance for Vaccines and Immunization (GAVI). from a country perspective. London, Save the Children UK.

The Global Fund (2007). Data Quality Assessment Tool. Guidelines for implementation by an auditing team.

The LATH Consortium (2001). Immunisation Data Quality Audit. Evaluation report. Final report. LATH.

The World Bank (1993). World Development Report 1993: investing in health. Oxford University Press.

UNa [homepage in the Internet]. Composition of macro geographical (continental) regions, geographical sub-regions, and selected economic and other groupings. Available from:

http://unstats.un.org/unsd/methods/m49/m49regin.htm (accessed 19/01/2006). UNb [homepage in the Internet]. UN Statistical Division. ISO ALPHA-3 code. Countries or areas, codes and abbreviations. Available from: http://unstats.un.org/unsd/methods/m49/m49alpha.htm\#ftna (accessed 27/10/05).

UNc [homepage in the Internet]. Statistical Division. September 2005. http://unstats.un.org/unsd/snaama/dnllist.asp (accessed 07/02/06).

Walt G, Buse K (2000). Editorial: partnership and fragmentation in international health: threat or opportunity? Tropical Medicine and International Health. 5(7), 467-71.

WHO (2003). The immunisation data quality audit (DQA) procedure. Geneva: Vaccines and Biologicals.

WHO (2004a). Immunisation in practice. A practical resource guide for health workers. 2004 Update.

WHO (2004b). The immunization data quality self-assessment (DQS) tool. WHO Document WHO/IVB/05.04. Geneva 2004.

WHO (2006). The reaching every district strategy. Fact sheet WHO / xx2006. $\mathrm{WHO}$.

WHO (2006). WHO vaccine-preventable diseases: monitoring system. 2006 global summary. Geneva: WHO - Immunisation, Vaccines and Biologials. WHO/UNICEF (2005). GIVS - Global Immunization Vision and Strategy 20062015. WHO. Available from: http://www.who.int/vaccinesdocuments/DocsPDF05/GIVS_Final_EN.pdf

Woodard S, Archer L, Zell E, Ronveaux O, Birmingham M (2007). Design and simulation study of the immunisation Data Quality Audit. Annals of Epidemiology. 17, 628-33. 